\title{
The Influence of Ring-Speed Ratio Dynamic Change on Nonlinear Vibration Response of High-Speed Turbocharger Rotor System
}

\author{
Guangfu Bin, ${ }^{1}$ Liang Zhang $\mathbb{D},{ }^{1}$ Feng Yang $\mathbb{D}^{2},{ }^{2}$ and Anhua Chen $\mathbb{D}^{1}$ \\ ${ }^{1}$ College of Mechanical Engineering, Hunan University of Science and Technology, Hunan 411201, Xiangtan, China \\ ${ }^{2}$ VÖFON Turbo Systems (Ningbo) Co. Ltd., Zhejiang, Ningbo 315336, China \\ Correspondence should be addressed to Anhua Chen; ahchen@hnust.edu.cn
}

Received 27 August 2021; Revised 25 September 2021; Accepted 29 September 2021; Published 28 October 2021

Academic Editor: Lei Hou

Copyright (C) 2021 Guangfu Bin et al. This is an open access article distributed under the Creative Commons Attribution License, which permits unrestricted use, distribution, and reproduction in any medium, provided the original work is properly cited.

The ring-speed ratio is a comprehensive dynamic index of floating ring bearing structure and operating parameters, which directly affects the dynamic behavior of the turbocharger rotor system. The cross stiffness of ring-speed ratio and floating ring bearing and the work of oil film force are analyzed. The influence of dynamic ring-speed ratio change on the vibration response of floating ring bearing was studied. The finite element model of the rotor-floating ring bearing system is constructed; its model parameters are verified through the measured critical rotor speed. Newmark integral method is used to analyze the nonlinear transient response. The results show that when the ring-speed ratio is between 0.18 and 0.24 , the rotor is in a good operating state; when it increases from 0.24 to 0.36 , the rotor vibration is dominated by frequency division, and the system will be less stable. The square of the ringspeed ratio is inversely proportional to the rotational speed of the journal where the subfrequency vibration occurs. It helps to know the nonlinear vibration by judging the journal speed when the rotor vibration occurs in subfrequency. The conclusion provides a reference for the mechanical dynamics design and intelligent management and maintenance of this kind of turbine rotors.

\section{Introduction}

Ring-speed ratio is the ratio of floating ring speed to rotor journal speed, which determines the stability and reliability of the rotor bearing system to a large extent, and its variation range is generally between 0.10 and 0.35 [1]. Therefore, it has become a key problem to be solved in high-speed rotor dynamics design to master the influence law of ring speed ratio on the vibration of the high-speed light-loaded turbocharger rotor system. Zhu et al. [2] established the dynamic model of the rotor-bearing system and analyzed the influence of rotor velocity, disk eccentricity, and stator stiffness on the response of rotor-bearing system. Li et al. [3] established a dynamic model of the rotor-bearing system considering nonuniform interface stiffness and studied the influence of bending stiffness on the stable operation of the rotor. San and Guo $[4,5]$ believed that the temperature and viscosity effect of floating ring bearings can reduce the ringspeed ratio and affect the stability of bearings. Li Jiaqi et al.
$[6,7]$ studied the influence of structural parameters on the ring speed ratio by considering the heat transfer factors among the rotating shaft, floating ring, and bearing housing. Shiyuan et al. [8] analyzed the influence of floating ring materials on the ring speed ratio and discussed the applicable scope of traditional analytic formula for ring speed ratio. Mokhtar [9] optimized the stability of floating ring bearings based on the short bearing theory and gave the optimization interval of relevant parameters. Koutsovasilis et al. [10] studied the vibration problem caused by floating ring bearings. Deligant et al. [11] predicted the performance of supercharger bearing through CFD software. Lee and Hong [12] studied the influence of inlet oil temperature and oil pressure on the speed of floating ring. Schweizer $[13,14]$ pointed out that the annular speed ratio was an important factor leading to the nonlinear vibration and instability of the turbocharger rotor. Wang et al. [15] studied the influence of the ultimate tolerance clearance of floating ring bearings on the vibration of turbocharger rotor system. Guangfu et al. 
[16] analyzed the dynamic behavior of the rotor-bearing system with internal damping composite materials under the action of temperature field, and the results showed that the increase of temperature field would generate tangential force for the damping of the rotor system, thus affecting the stability of the rotor system. Liu et al. [17] studied the influence of inlet oil temperature of the turbocharger rotor system on vibration response characteristics of the rotor subsystem. Peixoto et al. [18] studied the influence of temperature on vibration characteristics of the turbocharger rotor system. Dyk et al. [19] proposed and analyzed several linearization methods of forces acting on floating ring bearings and proved the nonlinear vibration of the rotor system in combination with campbell diagram. Yongfeng et al. [20] used the polynomial chaos expansion method to describe the uncertainty of hollow shaft cracked rotor system. The dynamic response of hollow shaft with uncertain crack was solved by combining harmonic balance and polynomial chaos expansion. Li et al. [21] studied the nonlinear vibration and stability of the rotor-blade system by multiple scales method. The above studies discussed the influence of floating ring bearing structure and operation parameters on the ring-speed ratio. Most of the researchers only consider the influence of fixed ring speed ratio on the nonlinear vibration of rotor and the stability of rotor system, the speed range, and the speed fluctuation of the turbocharger rotor and rarely consider the influence of the dynamic change of the ring-speed ratio on the stability of the turbocharger rotor system. Therefore, this paper systematically studies the influence of dynamically changing ring-speed ratio on the stability and nonlinear vibration characteristics of the high-speed light-load turbocharger rotor system.

In this paper, based on Reynolds equation and fluid lubrication theory, the dynamic characteristic coefficients of the inner and outer oil film of floating ring bearings are solved, and a dynamic finite element model of floating ring bearings is established. The relationship between the ringspeed ratio and the cross stiffness of floating ring bearings and that between the ring speed ratio and the oil film forces are studied. The finite element model of the floating ring bearing-rotor system dynamics is built simultaneously. The rationality of the finite element model parameters is verified by critical speed test. The vibration waterfall diagram and the amplitude of each order is analyzed, and the internal correlation between the dynamic change of ring-speed ratio and the vibration response of the rotor system is explored. According to the functional relationship between the ringspeed ratio and the journal speed when the subfrequency vibration occurs, the corresponding relationship between the subfrequency speed point and the ring-speed ratio is revealed, which provides a reference for the analysis and judgment of the rotor system stability.

\section{Theoretical Analysis of Dynamics of Floating- Ring Bearing Rotor System}

The floating ring bearing is different from the traditional sliding bearing in that the oil film is divided into inner and outer layers through the floating ring between the rotating journal and the fixed bearing seat, which reduces the relative speed between the journal and the bearing bush, reduces the friction power consumption, and improves the stability of the rotor system. Its structure is shown in Figure 1.

According to Reynolds equation, the dynamic pressure distribution equations of inner and outer oil film of floating ring bearing are obtained [22]:

$$
\begin{aligned}
\frac{1}{R_{j}} \frac{\partial}{\partial \theta_{i}}\left(\frac{H_{i}^{3}}{12 \mu_{i}} \frac{\partial p_{i}}{\partial \theta_{i}}\right)+\frac{\partial}{\partial Z_{i}}\left(\frac{H_{i}^{3}}{12 \mu_{i}} \frac{\partial p_{i}}{\partial \theta_{i}}\right)=\frac{\omega_{j}+\omega_{i}}{2} \frac{\partial H_{i}}{\partial \theta_{i}}+\frac{\partial H_{i}}{\partial t}, \\
\frac{1}{R_{0}} \frac{\partial}{\partial \theta_{0}}\left(\frac{H_{0}^{3}}{12 \mu_{0}} \frac{\partial p_{0}}{\partial \theta_{0}}\right)+\frac{\partial}{\partial Z_{0}}\left(\frac{H_{0}^{3}}{12 \mu_{0}} \frac{\partial p_{0}}{\partial \theta_{0}}\right)=\frac{\omega_{r}}{2} \frac{\partial H}{\partial \theta_{0}}+\frac{\partial H}{\partial t} .
\end{aligned}
$$

In the above equations, $i$ and $o$ represent the inner oil and outer oil film, respectively; $H$ is the oil film thickness; $P$ is the oil film dynamic pressure; $\mu$ is the oil film viscosity; $R_{o}$ and $R_{j}$ are the outer diameter and journal radius of the floating ring, respectively; $\omega_{j}$ and $\omega_{r}$ are the journal speed and floating ring speed, respectively.

Since the floating ring rotates with the journal at a certain speed, the ring-speed ratio $\gamma$ is the ratio of the floating ring speed $\omega_{r}$ to the journal speed $\omega_{j}$ :

$$
\text { ring speed ratio }=\frac{\omega_{r}}{\omega_{j}} .
$$

The dynamic pressure of the inner oil film in the floating ring bearing is related to $\omega_{j}+\omega_{r}$, the relative displacement of the floating ring and the journal $\bar{x}=x_{j}-x_{r}, \bar{y}=y_{j}-y_{r}$ and the relative velocity $\overline{\dot{x}}=\dot{x}_{j}-\dot{x}_{r}, \overline{\dot{y}}=\dot{y}_{j}-\dot{y}_{r}$. Similarly, the dynamic pressure of the outer oil film of the floating ring bearing is related to the rotational speed of the floating ring $\omega_{r}$, the displacement of the floating ring $x_{r}, y_{r}$, and the velocity of the floating ring $\dot{x}_{r}, \dot{y}_{r}$; then, the dynamic pressure of the inner and outer oil film of the floating ring bearing is expressed as [23]

$$
\begin{gathered}
p_{i}=\frac{3 \mu_{i}}{H_{i}^{3}}\left(z^{2}-\frac{L_{i}^{2}}{4}\right)\left[\omega_{j}(1+\gamma) \bar{x} \sin \theta_{i}-\omega_{j}(1+\gamma) \bar{y} \cos \theta_{i}\right]-\frac{6 \mu_{i}}{H_{i}^{3}}\left(z^{2}-\frac{L_{i}^{2}}{4}\right)\left(\overline{\dot{x}} \cos \theta_{i}+\overline{\dot{y}} \sin \theta_{i}\right), \\
p_{o}=\frac{3 \mu_{o}}{H_{o}^{3}}\left(z^{2}-\frac{L_{o}^{2}}{4}\right)\left(\gamma \omega_{j} x_{r} \sin \theta_{o}-\gamma \omega_{j} y_{r} \cos \theta_{o}\right)-\frac{6 \mu_{o}}{H_{o}^{3}}\left(z^{2}-\frac{L_{o}^{2}}{4}\right)\left(\dot{x}_{r} \cos \theta_{o}+\dot{y}_{r} \sin \theta_{o}\right) .
\end{gathered}
$$




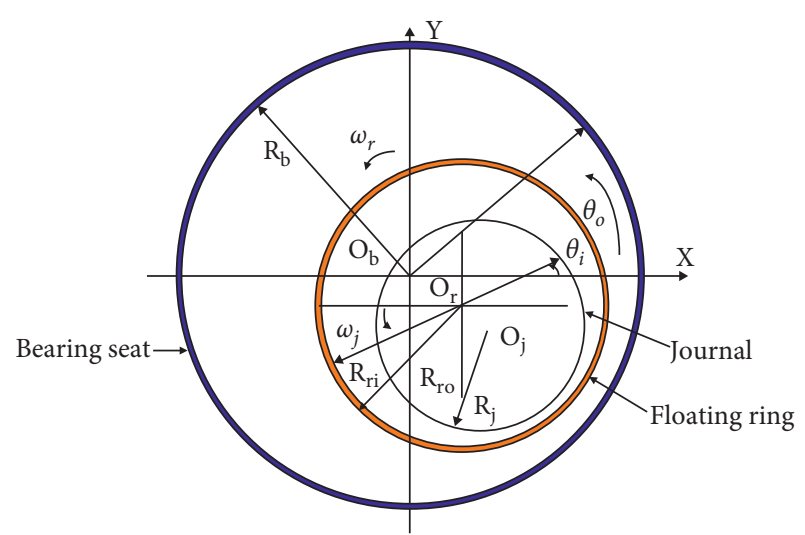

FIgURE 1: Float ring bearing structure plane.

With the bearing capacity of the floating ring bearing being considered, the expression of the inner and outer oil film forces of the floating ring bearing in actual operation is obtained as follows:

$$
\begin{gathered}
{\left[\begin{array}{l}
F_{i x} \\
F_{i y}
\end{array}\right]_{i}=\sigma_{i}\left\{\sum_{i=1}^{N_{\mathrm{pad}}} \int_{0}^{L_{i}} \int_{o}^{2 \pi} P_{i}\left[\begin{array}{c}
\cos \theta_{i} \\
\sin \theta_{i}
\end{array}\right] R_{i} \mathrm{~d} \theta \mathrm{d} z\right\},} \\
{\left[\begin{array}{l}
F_{o x} \\
F_{o y}
\end{array}\right]_{o}=\sigma_{o}\left\{\sum_{i=1}^{N_{\mathrm{pad}}} \int_{0}^{L_{o}} \int_{0}^{2 \pi} P_{o}\left[\begin{array}{c}
\cos \theta_{o} \\
\sin \theta_{o}
\end{array}\right] R_{o} \mathrm{~d} \theta \mathrm{d} z\right\},}
\end{gathered}
$$

where $\sigma_{i}$ and $\sigma_{o}$ are the Sommerfeld coefficients of the inner and outer oil film, $N_{\text {pad }}$ is number of pads, $\theta$ is the included angle between the initial angle and the termination angle of the oil film, and $L_{i}$ and $L_{o}$ are the inner and outer axial lengths of the floating ring, respectively.

Since the stiffness of the turbocharger rotor system is mainly determined by the oil film stiffness of the floating ring bearing, the inner and outer oil film stiffness coefficient can be obtained as follows combined with the inner and outer oil film dynamic pressure in equations (3) and (4):

$$
\begin{aligned}
& {\left[\begin{array}{l}
k_{x x} \\
k_{x y}
\end{array}\right]=\int_{0}^{L_{o}} \int_{0}^{2 \pi}-p_{i x}\left[\begin{array}{c}
\operatorname{Cos} \theta_{i} \\
\sin \theta_{i}
\end{array}\right] \mathrm{d} x \mathrm{~d} y,} \\
& {\left[\begin{array}{l}
k_{y x} \\
k_{y y}
\end{array}\right]=\int_{0}^{L_{o}} \int_{0}^{2 \pi}-p_{i y}\left[\begin{array}{c}
\operatorname{Cos} \theta_{i} \\
\sin \theta_{i}
\end{array}\right] \mathrm{d} x \mathrm{~d} y,} \\
& {\left[\begin{array}{c}
k_{x x} \\
k_{x y}
\end{array}\right]=\int_{0}^{L_{o}} \int_{0}^{2 \pi}-p_{o x}\left[\begin{array}{c}
\cos \theta_{0} \\
\sin \theta_{o}
\end{array}\right] \mathrm{d} x \mathrm{~d} y,} \\
& {\left[\begin{array}{l}
k_{y x} \\
k_{y y}
\end{array}\right]=\int_{0}^{L_{o}} \int_{0}^{2 \pi}-p_{o y}\left[\begin{array}{c}
\cos \theta_{o} \\
\sin \theta_{o}
\end{array}\right] \mathrm{d} x \mathrm{~d} y .}
\end{aligned}
$$

Through combining equations (3), (4), and (7), it is known that the ring-speed ratio would change the cross stiffness difference $\left(k_{x y}-k_{y x}\right)$ of the floating ring bearing. The difference of the cross stiffness coefficient determines the positive and negative work of the oil film force of the floating ring bearing, which plays a major role in the stability of the rotating subsystem [24]. In the one-circle vortex, if the oil film force does positive work, the oil film force can input energy to the rotor system, which may cause instability. Conversely, the rotor system is stable. The work of inner and outer oil film forces of floating ring bearings $W_{i}$ and $W_{o}$ is

$$
\begin{aligned}
& W_{i}=\pi a_{i} b_{i} \sin \varphi\left(k_{i x y}-k_{i y x}\right)-\pi\left(\omega_{j}-\gamma \omega_{j}\right)\left(c_{i x x} a_{i}^{2}+c_{i y y} b_{i}^{2}\right)-\pi\left(\omega_{j}-\gamma \omega_{j}\right) a_{i} b_{i} \cos \varphi\left(c_{i x y}+c_{i y x}\right), \\
& W_{o}=\pi a_{o} b_{o} \sin \varphi\left(k_{o x y}-k_{o y x}\right)-\pi \gamma \omega_{j}\left(c_{o x x} a_{o}^{2}+c_{o y y} b_{o}^{2}\right)-\pi \gamma \omega_{j} a_{o} b_{o} \cos \varphi\left(c_{o x y}+c_{o y x}\right) .
\end{aligned}
$$

In this equation, $\pi a b \sin \varphi$ represents the area of the vortex trajectory of the inner and outer oil film, $c$ is the damping coefficient, and $\varphi$ is the rotation angle, $a$ is the major axis of the ellipse, and $b$ is the minor axis of the ellipse.

According to the above analysis, it can be concluded that the ring-speed ratio mainly changes the inner and outer oil film pressure of the floating ring bearing and the cross stiffness of the rotor system, which affects the response of the turbocharger floating ring bearing and rotor system under nonlinear vibration.

\section{FEM Modeling and Its Experimental Analysis}

3.1. FRB Dynamic Characteristics Based on $\gamma$. The load of bearing at the turbine end of turbocharger rotor is greater than that at the impeller end, and bearing instability generally occurs at the turbine end first. Therefore, the floating ring bearing at the turbine end is mainly analyzed. Its structural parameters are shown in Table 1, in which the length unit is $\mathrm{mm}$ and the mass unit is $\mathrm{g}$.

According to the structural parameters in Table 1, a dynamic finite element model of floating ring bearings is established, as shown in Figure 2.

The stability of the floating ring bearing will be changed due to the dynamic change of the ring-speed ratio during the operation, and the difference between the inner and outer oil film stiffness of the floating ring bearing is the main reason that causes the instability of the bearing. Through the analysis of the finite element model of floating ring bearing, the variation of the cross stiffness difference of floating ring bearing with the speed in the range of ring-speed ratio from 0.18 to 0.36 is obtained, as shown in Figure 3 .

The difference of cross stiffness and equivalent cross stiffness of the inner and outer oil film increases together with the rotating speed and the ring-speed ratio. By comparing (a) and (b) in Figure 3, it is found that the difference of the inner oil film cross rigidity $\left(k_{i x y}-k_{i y x}\right)$ is much larger 
TABLE 1: Structural parameters of floating ring bearing.

\begin{tabular}{ll}
\hline Shaft diameter & 6.000 \\
\hline Bearing diameter & 9.600 \\
The quality of floating ring & 2.160 \\
Length of the inner ring & 3.600 \\
Length of the outer ring & 6.150 \\
Floating ring inside diameter & 6.016 \\
Floating ring outside diameter & 9.540 \\
\hline
\end{tabular}

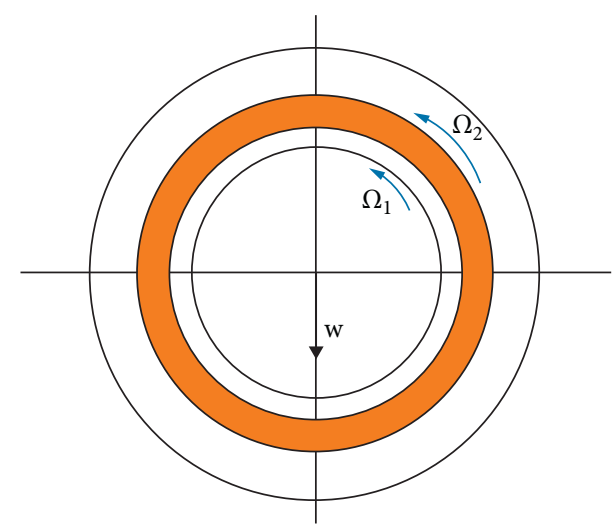

Figure 2: Dynamic model of floating ring bearing.

than that of the outer oil film cross rigidity $\left(k_{o x y}-k_{\text {oyx }}\right)$, and that of the equivalent cross rigidity $\left(k_{x y}-k_{y x}\right)$ in Figure (c) is slightly larger than that of the outer oil film cross stiffness due to the high rotational speed of the floating ring containing mass and the rotating shaft. The cross stiffness of the rotor system is generally determined by the cross stiffness of the floating ring bearing, while the cross stiffness of the floating ring bearing is determined by the relatively small cross stiffness of the outer oil film, which is similar to the series sliding bearing. According to the analysis of formula (8) and (9) from the perspective of work, the elastic force corresponding to the main stiffness coefficient of the inner and outer oil film is the conservative force, and the work is zero in a circle of vortex. The elastic force corresponding to the cross stiffness $k_{x y}$ and $k_{y x}$ is nonconservative force, which determines the positive and negative work of the inner and outer oil film force. If $k_{x y}-k_{y x}>0$, it can input energy to the rotor system, which can cause the instability of the rotor system and vice versa. As can be seen from Figure 3, the cross stiffness difference of floating ring bearing is always over zero, and the difference increases as the ring-speed ratio does. It is indicated that the lager the ring-speed ratio is, the worse the stability of floating ring bearing will be, and the smaller the threshold value of instability speed will be.

3.2. Rotor Dynamics Modeling. According to the structure model of the rotor system in Figure 2, finite element idea is applied to divide the rotor system into several units along the axis of the rotor system, each of them being connected with nodes. Therefore, the finite element model of the turbocharger rotor-floating ring bearing system is constructed, which is shown as Figure 4. The finite element model has two wheels, 22 nodes among which node 9 and 12 are support centers of the floating bearing; node 19 is a lock nut, and node 21 and 22 are floating rings.

3.3. Experiment and Verification. To verify the correctness of the finite element model of the turbocharger rotor-floating ring bearing system, the speed increase test bench of the turbocharger is built up as shown in Figure 5. Pressure vortex impeller shell is punched; the photoelectric sensor and the two eddy current sensors are placed in the volute, and the eddy current sensor is vertically placed on the pressure of the impeller, being installed and fixed $0.3 \mathrm{~mm}$ away from the lock nut, which is as shown in Figure 6.

The Bode diagram at the locking nut is obtained through finite element model simulation calculation and turbocharger speed increase experiment, and the critical speed of the rotor system is compared and verified, as shown in Figures 7 and 8.

As seen from Figures 7 and 8, the journal speed of the amplitude peak of the rotor system in the simulation is about $58 \mathrm{krpm}$, and the phase difference changes about $120^{\circ}$. The journal speed of the amplitude peak measured in the experiment is about $57 \mathrm{krpm}$, and the phase difference changes about $180^{\circ}$, indicating that the first-order critical speed of the turbocharger rotor is about $57 \mathrm{krpm}$. The simulation results are in good agreement with the experiments, which verifies the rationality of the selection of the parameters of the rotorfloating ring bearing system finite element model.

\section{Harmonic Response Analysis of the Turbocharger Rotor System}

4.1. Rotor System Response Analysis under Different RingSpeed Ratios. The nonlinear vibration law of the turbocharger rotor system under different ring-speed ratios is studied. The unbalance of 0.30 g.mm is applied at the node 4 of the finite element model (turbine leading edge) as the initial excitation of the system. The rotor system speed range is $10 \sim 200 \mathrm{krpm}$. Under this working condition, the rotor system with the ring-speed ratio of $0.18,0.24,0.30$, and 0.36 is operated. Through the analysis of each element, the relationship between node force and node displacement is established. Through the analysis of the Newmark integral method, the three-dimensional vibration waterfall diagram at the end node 19 of the impeller under different ring-speed ratios is obtained, as shown in Figure 9.

\subsection{Discussion and Analysis.}

(1) Comparison of frequency domain values under the dynamic change of ring-speed ratio: before the ringspeed ratio reaches 0.18 , the rotor system all exhibits the same frequency vibration, and no subfrequency vibration occurs. When the ring-speed ratio increases from 0.24 to 0.36 , the rotor system has subfrequency vibration in the high-speed range, and the journal speed of frequency division vibration is about $48 \%$ earlier, and the subfrequency value of 


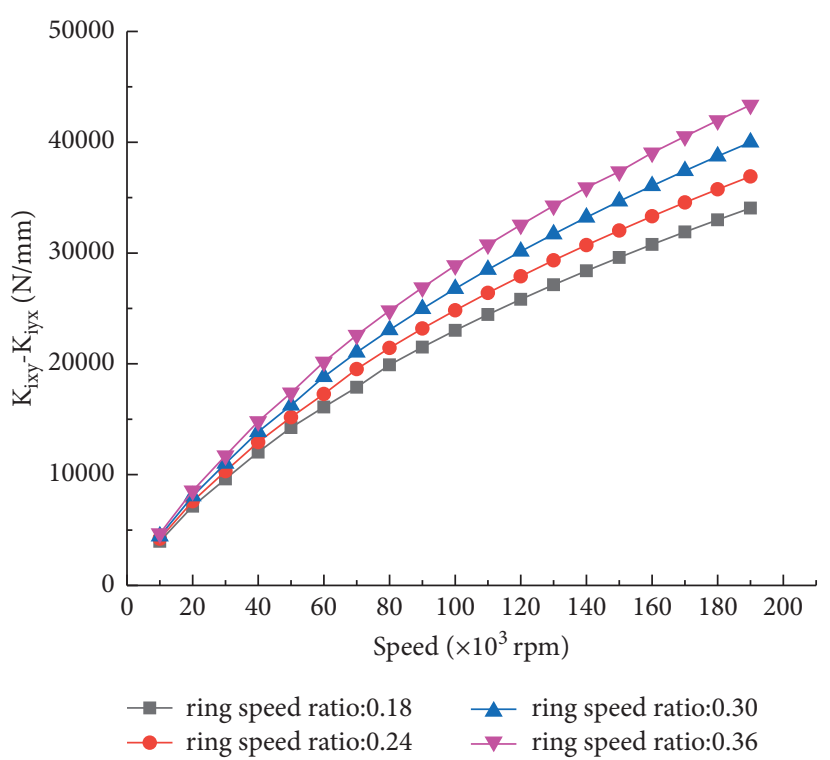

(a)

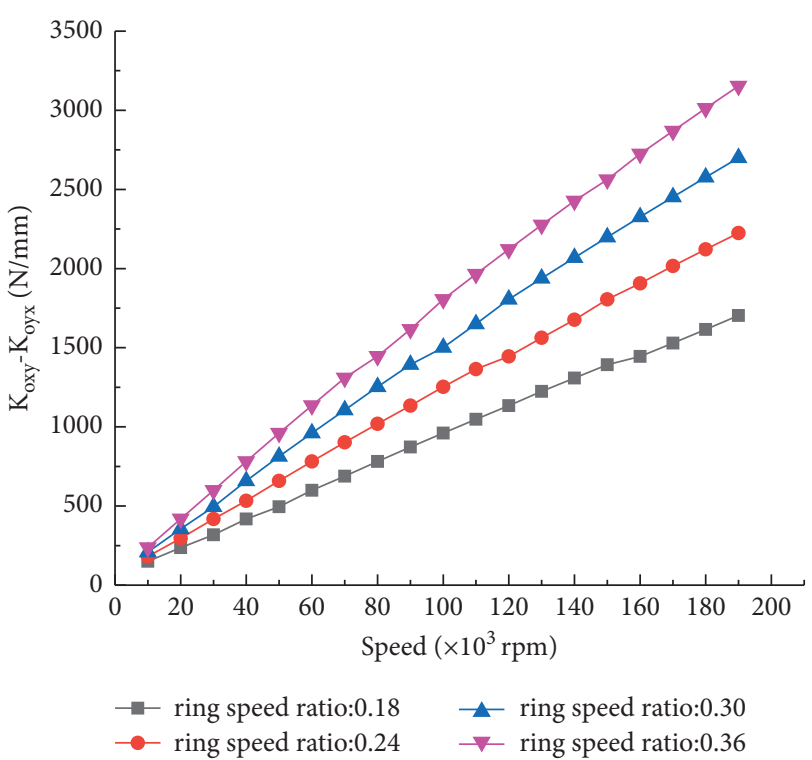

(b)

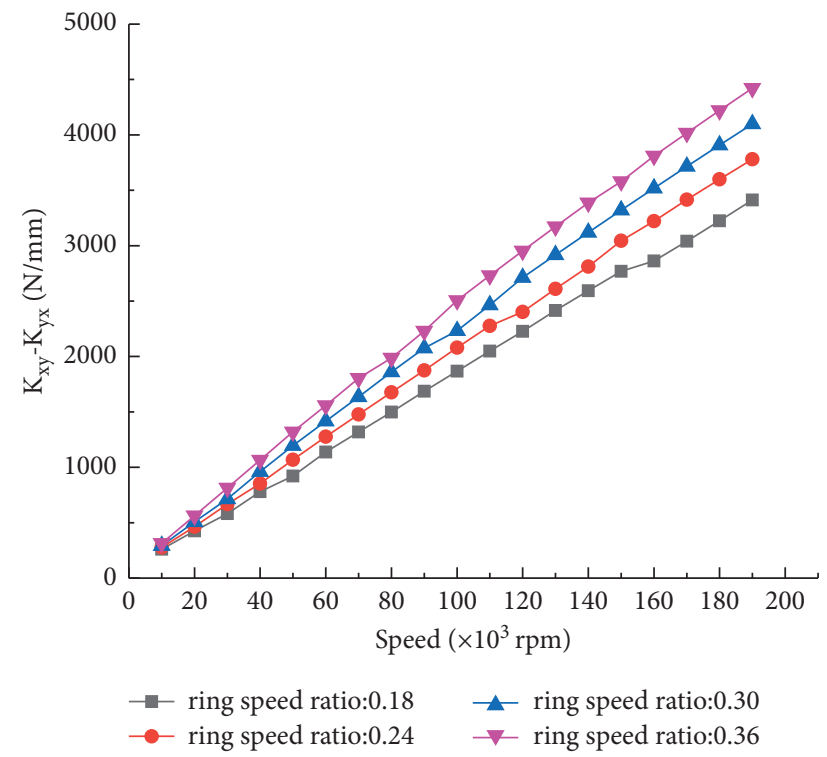

(c)

Figure 3: The relationship between the difference of cross stiffness of bearing at different ring speed ratios. (a) Cross stiffness difference $k_{i x y}-k_{i y x}$ of inner oil film. (b) Cross stiffness difference $k_{o x y}-k_{o y x}$ of outer oil film. (c) Equivalent cross stiffness difference $k_{x y}-k_{y x}$.

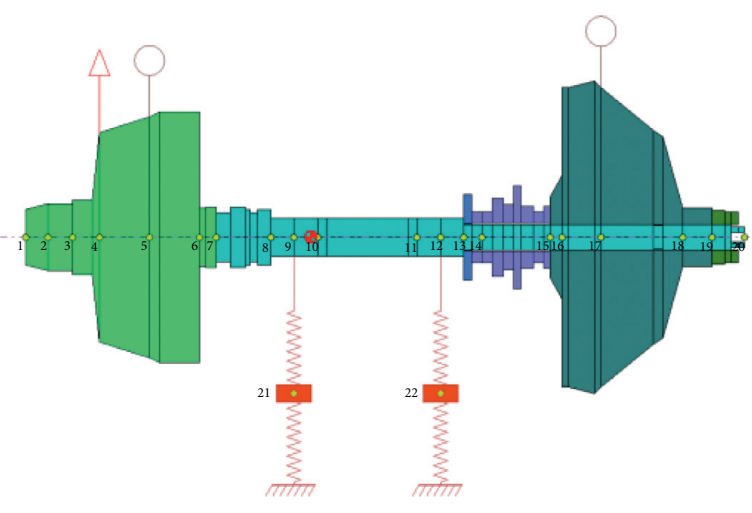

FIGURE 4: FEM of the rotor-floating ring bearing system. subfrequency vibration is about half of the ringspeed ratio. For example, when the ring-speed ratio is $0.24,0.30$, and 0.36 , subfrequency vibration frequency is about $0.12 \mathrm{x}, 0.15 \mathrm{x}$, and $0.18 \mathrm{x}$ of the power frequency.

(2) The influence of the dynamic change of the ringspeed ratio on the amplitude: according the nonlinear transient response analysis, the variation under the same frequency amplitudes and the subfrequency amplitudes of the rotor system with different ring-speed ratios are shown in Figure 10. When the ring-speed ratio is 0.18 , the same frequency amplitude of the rotor system is basically the same, and its amplitude increases first and then 


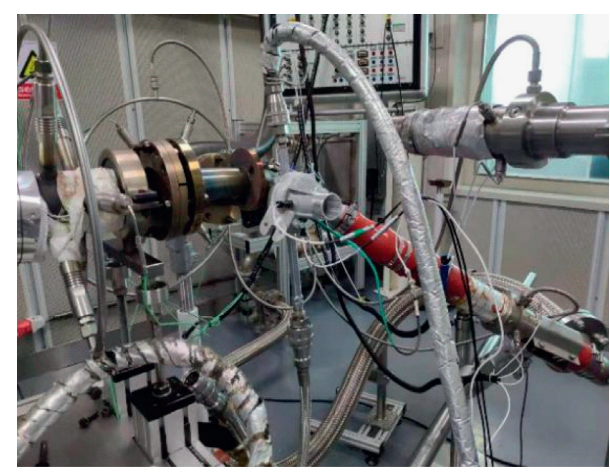

FIGURE 5: Turbocharger speed test bench.

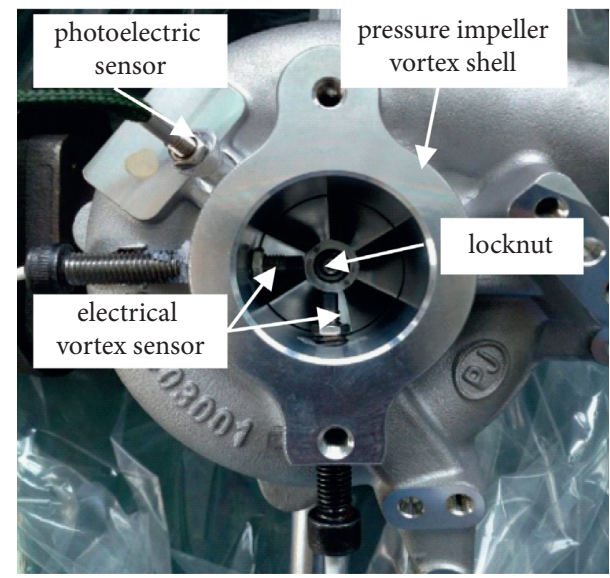

FIgURE 6: Installation diagram of pressure impeller end sensor.

decreases with the speed. Moreover, when the journal speed with the maximum amplitude of the same frequency is about $60 \mathrm{krpm}$, it is basically consistent with the above critical speed of $57 \mathrm{krpm}$. The correctness of the finite element model is further verified from the perspective of nonlinear analysis. As it can be seen from Figure 10(b), the subfrequency amplitude increases sharply when the ring-speed ratio increases from 0.30 to 0.36 . When the ringspeed ratio is between 0.30 and 0.36 , the subfrequency amplitude is much larger than the same frequency amplitude, which plays a leading role in the vibration of the rotating subsystem.

(3) Judgment of rotor stability by dynamic change of ring-speed ratio: for nonlinear high-speed rotor systems, in general, if the subfrequency vibration amplitude exceeds $6 \mu \mathrm{m}$ and is greater than $1 / 3$ of the overall amplitsude, attention should be paid from the perspective of instability [25]. According to Figures 9 and 10 , when the ring-speed ratio is 0.18 , the rotor system only has the same frequency vibration caused by unbalance, and no subfrequency vibration occurs, and the rotor system is stable. When the ring-speed ratio is between 0.30 and 0.36 , the maximum subfrequency vibration of the rotor system is about 11 times of that of the same frequency vibration and

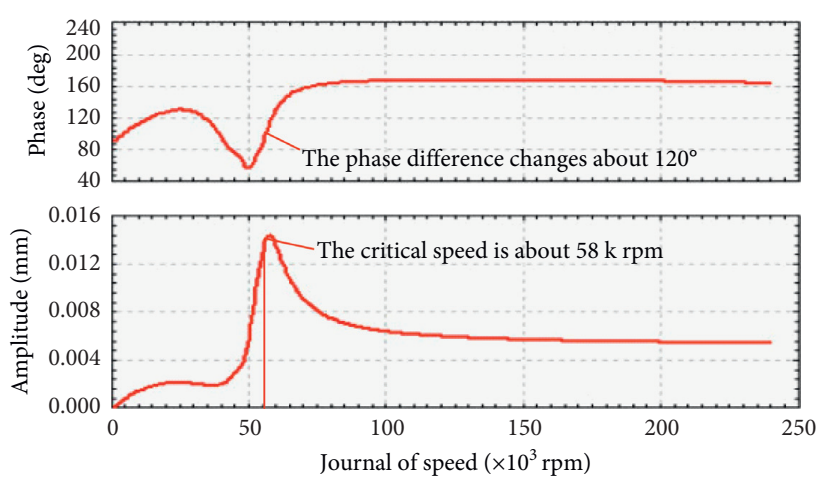

Figure 7: Bode diagram of the finite element model node 19 of turbocharger.

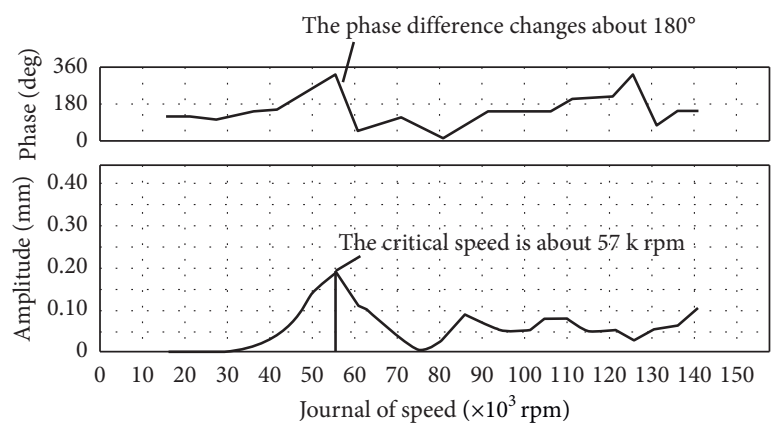

FIgURE 8: Bode diagram of the rotor system locking nut of turbocharger.

tends to be unstable. According to the working characteristics of the floating ring bearing, increasing the floating ring can improve the lubricating oil flow, which is beneficial to cool the bearing, enhance the static lubrication characteristics, reduce the relative speed between the journal and the bearing seat, reduce the friction power consumption of the bearing, make the inner and outer oil film of the floating ring bearing more easily in the state of dynamic lubrication, and improve the bearing capacity of the floating ring bearing. Analyzing the vibration response amplitude of the rotor system under each ring-speed ratio, the system stability is better when the ring-speed ratio is between 0.18 and 0.30 .

(4) The functional relationship between the ring-speed ratio and the current journal speed of frequency division: the instability threshold of the rotor system is closely related to the journal speed when subfrequency vibration occurs, so the relationship between the ring-speed ratio and the journal speed is analyzed when subfrequency vibration occurs is analyzed. From the data analysis in Table 2, it can be seen that there is a functional relationship between the square of the ring-speed ratio $\gamma$ and the journal speed $N$ when subfrequency vibration occurs, $N \times \gamma^{2}=T$, where $T$ is a constant value. According to the analysis, the fixed value $T$ of this type of rotor is 


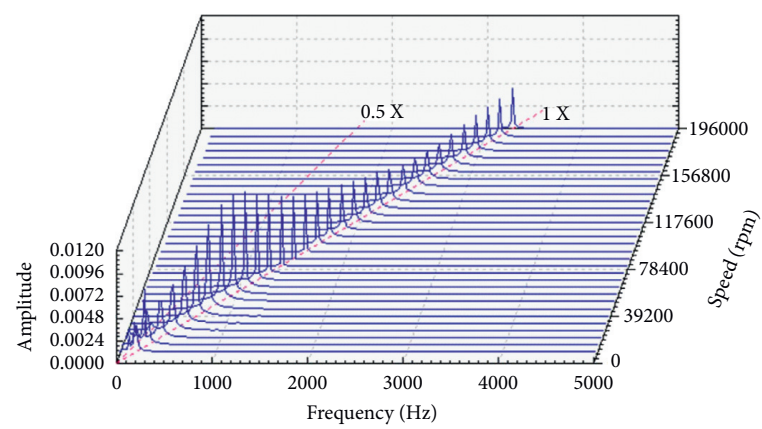

(a)

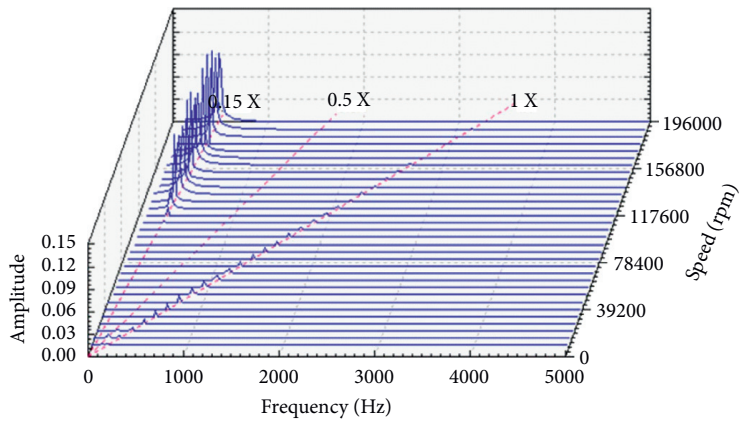

(c)

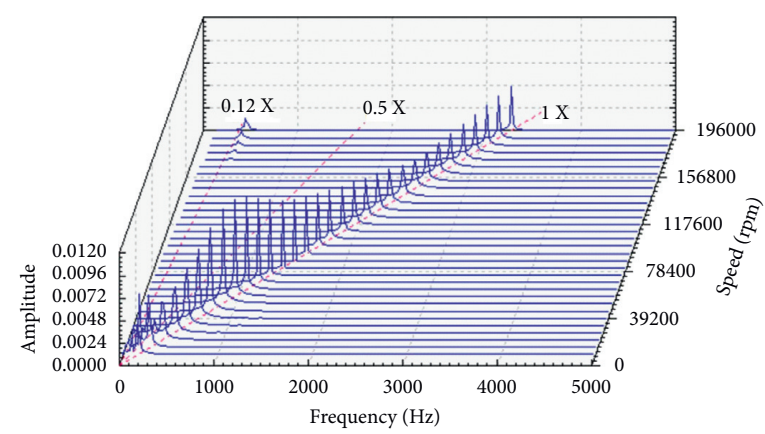

(b)

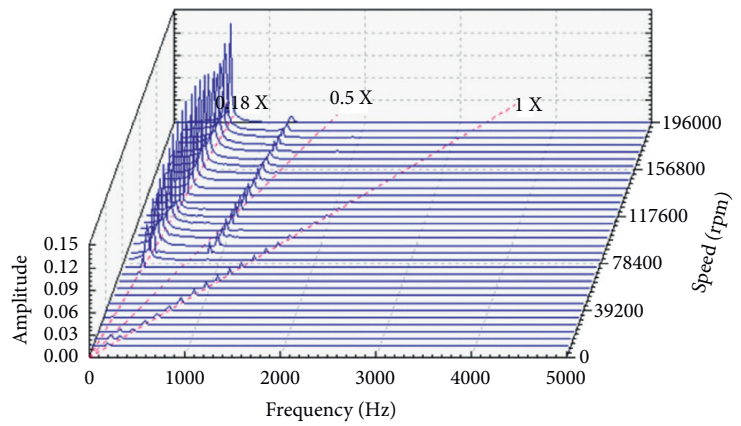

(d)

Figure 9: Vibration waterfall diagram of the rotor system with different ring-speed ratios. (a) Ring speed ratio: 0.18. (b) Ring speed ratio: 0.24. (c) Ring speed ratio: 0.30 . (d) Ring speed ratio: 0.36 .

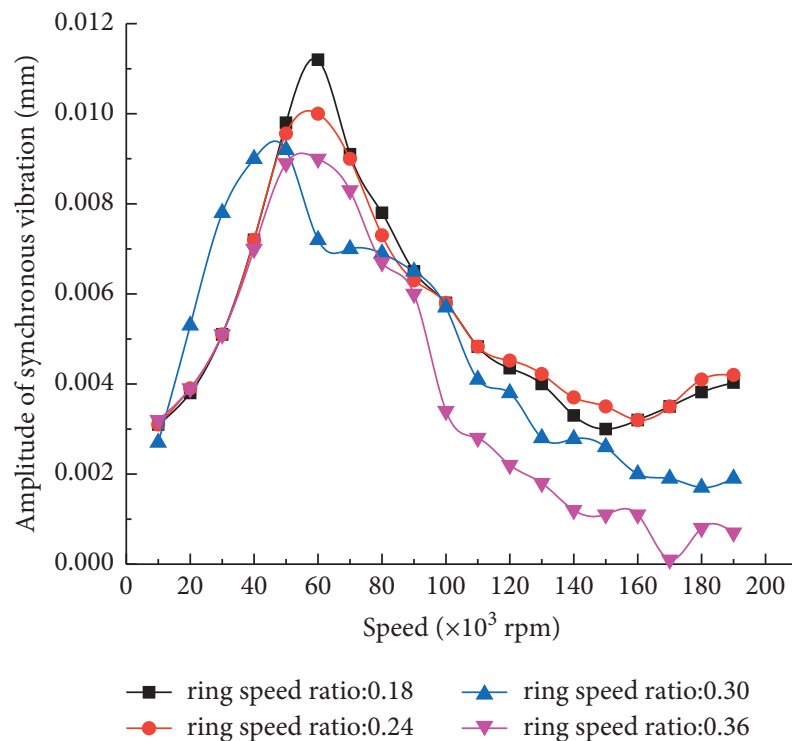

(a)

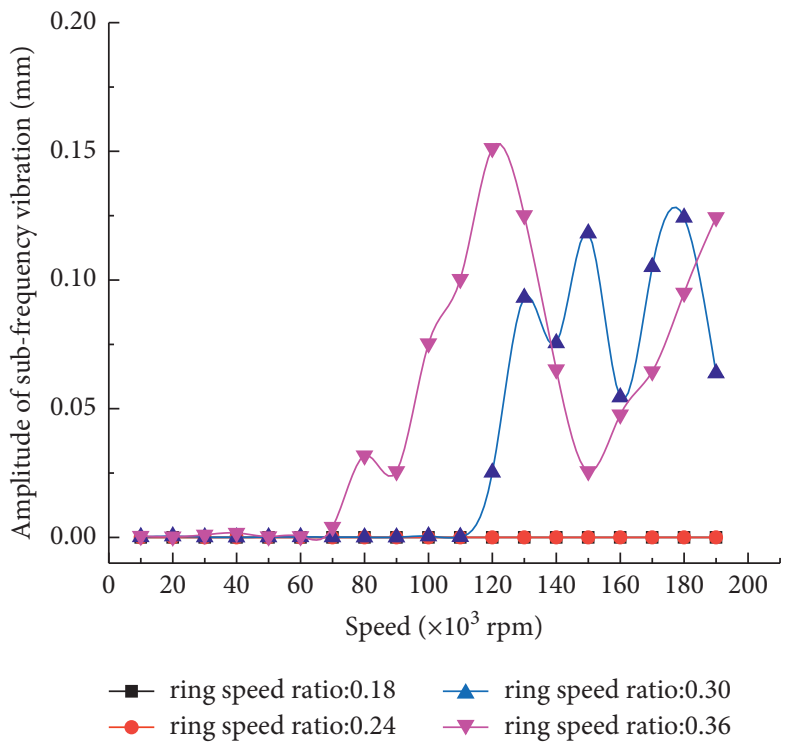

(b)

Figure 10: Vibration amplitudes of the rotor system with different ring speed ratios. (a) $1 \mathrm{x}$ amplitude of vibration at the same frequency. (b) Main frequency division vibration amplitude.

TABle 2: Data of different ring-speed ratios and journal speed.

\begin{tabular}{lcc}
\hline Frequency division of the journal speed, $N(\mathrm{rpm})$ & Ring speed ratio, $\gamma$ & Definite value, $T(\mathrm{rpm})$ \\
\hline $160000-130000$ & $0.250-0.275$ & $10000-9831$ \\
$109000-94000$ & $0.300-0.325$ & $9810-9928$ \\
82000 & 0.350 & 10045 \\
\hline
\end{tabular}


about $10000 \mathrm{rpm}$. When the basic structure and operating parameters of the rotor system are set, the ring-speed ratio $\gamma$ and the constant value $T$ can be roughly determined. Then, the ring-speed ratio $\gamma$ and the constant value $T$ can be used to predict the journal speed $N$ when the subfrequency vibration occurs. It is helpful to assist in judging the stability of the rotor system, so as to understand the nonlinear vibration of the turbocharger rotor system.

\section{Conclusions}

(1) It aims at the nonlinear vibration of the high-speed turbocharger rotor system caused by annular speed ratio. Based on the analysis of the influence of ringspeed ratio on the stability of floating ring bearing, a rotor-floating ring bearing dynamics finite element model is established. The correctness of the finite element model is verified by the measured critical speed. By analyzing the stability of the rotor subsystem based on the rotor system finite element simulation and turbocharger critical speed experiment, it is found that the dynamic change of ringspeed ratio is obviously different in the stability and vibration amplitude of the rotor subsystem.

(2) The influence law of the dynamic change of annular speed ratio on the nonlinear vibration of the highspeed turbocharger rotor system is summarized. When the ring-speed ratio increases from 0.30 to 0.36 , the rotor is dominated by frequency division, and the journal speed of subfrequency vibration is about $48 \%$ earlier, which affects the stability of the rotor system. When the ring-speed ratio is between 0.18 and 0.30 , the rotor is in a good operating state. It is concluded that the square of the ring speed ratio is inversely proportional to the journal speed when the subfrequency vibration occurs. The rotor stability can be judged by the journal speed when the subfrequency vibration occurs. The smaller the ring-speed ratio is in a certain range, the better the stability of the rotor bearing and the better the performance of the system will be.

(3) Due to the large range of speed change of the turbocharger rotor and to the fact that the floating ring is in a closed cavity, it is unable to directly measure the speed of the floating ring through the experiment. Therefore, many are to be further studied in the future including the influence laws of model validation and ring-speed ratio on the nonlinear vibration response of the turbocharger rotor system, so as to further control ring-speed ratio dynamic change trend of ring-speed ratio and improve the influence law on the nonlinear vibration of the rotor system of the high-speed turbocharger.

\section{Data Availability}

All the data used to draw the figures and support the conclusions of the manuscript are generated by calculating the model established in the manuscript. The calculation result data used to support the findings of this study are available from the first author (Guangfu Bin) upon request.

\section{Conflicts of Interest}

The authors declare that there are no conflicts of interest regarding the publication of this paper.

\section{Acknowledgments}

This work was supported by the https://doi.org/10.13039/ 501100001809National Natural Science Foundation of China (Grant no. 52075165); the science and technology innovation Program of Hunan Province (Grant no. 2020RC4039); Natural Science Foundation of Hunan Province (Grant no. 2019JJ40084); and Key Scientific Research Project of Hunan Province Education Department (Grant no. 19A171).

\section{References}

[1] W. J. Chen, Introduction to Dynamics of Rotor-Bearing Systems, Trafford Publishing, Bloomington, IND, USA, 2007.

[2] Y. Zhu, Z. Wang, Q. Wang, X. Liu, H. Zang, and L. Wang, "Nonlinear dynamic analysis of rotor rub-impact system," Shock and Vibration, vol. 2019, Article ID 4867364, 20 pages, 2019.

[3] J. Li, Y. Li, F. Zhang, and Y. Feng, "Nonlinear analysis of rod fastened rotor under nonuniform contact stiffness," Shock and Vibration, vol. 2020, Article ID 8851996, 10 pages, 2020.

[4] L. San Andrés and J. Kerth, "Thermal effects on the performance of floating ring bearings for turbochargers," Proceedings of the Institution of Mechanical Engineers-Part J: Journal of Engineering Tribology, vol. 218, no. 5, pp. 437-450, 2004.

[5] H. Guo, S. Yang, S. Zhang, and Z. Zhang, "Influence of temperature-viscosity effect on ring-journal speed ratio and stability for a hydrodynamic floating ring bearing," Industrial Lubrication \& Tribology, vol. 71, no. 4, pp. 540-547, 2019.

[6] J. Li, J. Ni, X. Shi, and X. Xu, "Study on factors affecting lubrication and heat dissipation performance of floating ring bearing in turbocharger," Journal of Mechanical Engineering, vol. 53, no. 17, pp. 141-148, 2017.

[7] L. Jia-qi, J.-M. Ni, X. Shi et al., "Effect of structural parameters on lubrication performance of floating ring bearing and ring speed ratio in turbocharger," Transactions of the Chinese Society of Agricultural Engineering, vol. 33, no. 2, pp. 48-55, 2017.

[8] P. Shi-yuan, H. Xu, and S. Fang-hui, "Study on static thermohydrodynamic lubrication of floating ring bearing," Journal of Mechanical Engineering, vol. 53, no. 23, pp. 108-115, 2017.

[9] M. O. A. Mokhtar, "Floating ring journal bearings: theory, design and optimization," Tribology International, vol. 14, no. 2, pp. 113-119, 1981.

[10] P. Koutsovasilis, N. Driot, D. Lu, and B. Schweizer, "Quantification of sub-synchronous vibrations for turbocharger rotors with full-floating ring bearings," Archive of Applied Mechanics, vol. 85, no. 4, pp. 481-502, 2015.

[11] M. Deligant, P. Podevin, and G. Descombes, "CFD model for turbocharger journal bearing performances," Applied Thermal Engineering, vol. 31, no. 5, pp. 811-819, 2011. 
[12] I.-B. Lee and S.-K. Hong, "Effects of oil inlet pressure and temperature on the dynamic behaviors of a full-floating ring bearing supported turbocharger rotor," The KSFM Journal of Fluid Machinery, vol. 20, no. 2, pp. 53-62, 2017.

[13] B. Schweizer, "Total instability of turbocharger rotors-physical explanation of the dynamic failure of rotors with fullfloating ring bearings," Journal of Sound and Vibration, vol. 328, no. 1-2, pp. 156-190, 2009.

[14] B. Schweizer and M. Sievert, "Nonlinear oscillations of automotive turbocharger turbines," Journal of Sound and Vibration, vol. 321, no. 3-5, pp. 955-975, 2009.

[15] L. Wang, G. Bin, X. Li, and X. Zhang, "Effects of floating ring bearing manufacturing tolerance clearances on the dynamic characteristics for turbocharger," Chinese Journal of $\mathrm{Me}$ chanical Engineering, vol. 28, no. 3, pp. 530-540, 2015.

[16] B. Guangfu, H. Yuan, Z. Xinli, Y. Feng, and M. Zhengyu, "Effect of inlet oil temperature on vibration characteristics of high-speed light-load turbocharger rotor under long period and variable speed," Journal of Mechanical Engineering, vol. 56, no. 21, pp. 131-139, 2020.

[17] Z. Liu, R. Wang, F. Cao, and P. Shi, "Dynamic behaviour analysis of turbocharger rotor-shaft system in thermal environment based on finite element method," Shock and Vibration, vol. 2020, Article ID 8888504, 18 pages, 2020.

[18] T. F. Peixoto, R. Nordmann, and K. Lucchesi Cavalca, "Dynamic analysis of turbochargers with thermo-hydrodynamic lubrication bearings," Journal of Sound and Vibration, vol. 505, 2021.

[19] Š. Dyk, L. Smolík, and R. Jan, "Predictive capability of various linearization approaches for floating-ring bearings in nonlinear dynamics of turbochargers," Mechanism and Machine Theory, vol. 149, 2020.

[20] Y. Yongfeng, W. Qinyu, W. Yanlin, Q. Weiyang, and L. Kuan, "Dynamic characteristics of cracked uncertain hollow-shaft," Mechanical Systems and Signal Processing, vol. 124, pp. 36-48, 2019.

[21] B. Li, H. Ma, X. Yu, J. Zeng, X. Guo, and B. Wen, "Nonlinear vibration and dynamic stability analysis of rotor-blade system with nonlinear supports," Archive of Applied Mechanics, vol. 89, no. 7, pp. 1375-1402, 2019.

[22] Y.-j. Lü, Y.-f. Zhang, Y.-b. Yu, and L. Yu, "Nonlinear dynamics of flexible rotor system supported on fixed-tilting pad combination journal bearing," Journal of Central South University, vol. 18, no. 3, pp. 610-617, 2011.

[23] L. Tian, W. J. Wang, and Z. J. Peng, "Dynamic behaviours of a full floating ring bearing supported turbocharger rotor with engine excitation," Journal of Sound and Vibration, vol. 330, no. 20, pp. 4851-4874, 2011.

[24] Z. Wang, Rotor Dynamics Design of Rotating Machinery, Tsinghua university press, Beijing, China, 2015.

[25] W. J. Chen, Practical Rotor Dynamics and Fluid Film Bearing Design, Eigen Technologies, London, UK, 2015. 